\title{
SINGLET OXYGEN: A REAGENT IN ORGANIC SYNTHESIS
}

\author{
G. OHLOFF \\ Firmenich SA, Research Division, Geneva, Switzerland
}

\begin{abstract}
In the introduction, the generation, the electronic state and the reaction of singlet oxygen $\left({ }^{1} \mathrm{O}_{2}\right)$ with carbon-carbon double bonds is described. For preparative purposes, ${ }^{1} \mathrm{O}_{2}$ is generated by dye-sensitized excitation of oxygen $\left({ }^{3} \mathrm{O}_{2}\right)$. The photo-oxygenation reaction leads to the formation of peroxides, which can be used as intermediates in the organic synthesis. Described are processes of preparation of important flavours and fragrances: inter alia, the synthesis of ascaridole (8), pear ester (24), galbanolene (25), rose oxide (73 and 74), damascenone (83), nootkatone (97), norcetone 100 from vetiver oil, geijerone (105) and the new musk fragrance 2,5-dioxacyclohexadecan-1, 6-dione (111). The role of ${ }^{1} \mathrm{O}_{2}$ as a biomimetic agent is mentioned in a few examples.
\end{abstract}

\section{INTRODUCTION}

The generation, properties and reactions of singlet oxygen $\left({ }^{1} \mathrm{O}_{2}\right)$ have been the subject of much theoretical interest, particularly in the last ten years ${ }^{1}$. It is therefore all the more surprising that the use of this species in synthetic organic chemistry has hitherto received little attention. With the aid of a few selected examples, mainly from our own laboratory, I should like to show you some of the possibilities opened up by the use of singlet oxygen in preparative organic chemistry. We started by introducing oxygen functions into molecules possessing one or two reactive $\mathrm{C}=\mathrm{C}$ double bonds.

At present we know three different types of reaction which ${ }^{1} \mathrm{O}_{2}$ can undergo with olefinic acceptor systems (Figure 1). In the simplest case A, which is also the most recent one known, ${ }^{1} \mathrm{O}_{2}$ attacks a double bond in a $[2+2]$ dipolar cyclo-addition to give 1,2-dioxetan (2). Three years ago, Schaap and Bartlett ${ }^{2}$ found that this type of ${ }^{1} \mathrm{O}_{2}$ reaction occurs with diethoxy ethylene (1), and Mazur and Foote ${ }^{3}$ have observed the same reaction with tetramethoxy ethylene. 1,2-Dioxetanes are thus only formed from electronrich double bonds, so case $A$ is a rather restricted one.

With respect to normal olefinic double bonds - as in case $\mathrm{C}-{ }^{1} \mathrm{O}_{2}$ behaves like an enophile $e^{4}$. This type of reaction leads to the formation of allyl hydroperoxides (6). Three carbon atoms are involved in this reaction. ${ }^{1} \mathrm{O}_{2}$ adds to one end of the double bond of 5 , while at the same time an allylic hydrogen is abstracted. The one-reaction is probably concerted, since it occurs with high stereospecificity. The geometry of the transition state is characterized by the axial attack of the singlet oxygen on the double bond and the axial 
G. OHLOFF

A

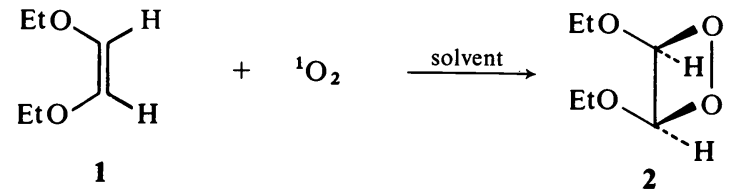

B<smiles>CC1=CC=C(C)CC1</smiles>

$+\quad{ }^{1} \mathrm{O}_{2}$

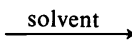<smiles>CC12C=CC(C)(OC1)OO2</smiles>

3

C<smiles>C=CC(C)=C(C)C</smiles>

5

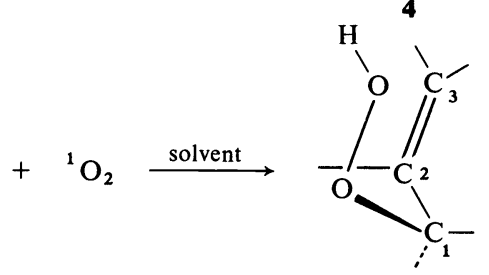

6

Figure 1. Singlet oxygen $\left({ }^{1} \mathrm{O}_{2}\right)$ reactions with $\mathrm{C}=\mathrm{C}$ double bonds. A : 1,2-dioxetan (2) formation $([2+2]$-cyclo-addition); B: 1, 4-endoperoxide (4) formation $([4+2]$-cyclo-addition); $\mathrm{C}$ : allylic hydroperoxide (6) formation ('ene-reaction')

detachment of the allylic hydrogen ${ }^{5}$. The direction and rate of the photooxygenation depend on the environment and degree of substitution of the olefinic double bond of 5. Thus, tetra-substituted ethylenic bonds are attacked most rapidly by ${ }^{1} \mathrm{O}_{2}$.

Finally ${ }^{1} \mathrm{O}_{2}$ reacts with cyclic 1,3 -diene systems $(3)$ by [4 +2$]$ cycloaddition (case B) - that is, by Diels-Alder addition ${ }^{1}$ - to give bridged peroxides (4).

\section{NATURE AND GENERATION OF SINGLET OXYGEN}

For a better understanding of the chemical behaviour of ${ }^{1} \mathrm{O}_{2}$, it is necessary to discuss briefly the generation and electronic state of this species. When we speak of ${ }^{1} \mathrm{O}_{2}$, we are thinking of molecular oxygen in the first excited state $\left({ }^{1} \Delta_{g}\right)$, which has an energy of about $22 \mathrm{kcal}$ above the ground state. The highest jccupied orbitals contain two paired electrons which are located in a single orbital, leaving the other vacant (Figure 2). In this metastable singlet state, oxygen is diamagnetic, and two-electron reactions should be expected from it. On the contrary, molecular $\mathrm{O}_{2}$ in the ground state is paramagnetic. Both electrons are distributed over two orbitals in a parallel arrangement. Hence, molecular $\mathrm{O}_{2}$ in the ground state behaves like a diradical, which might obviously undergo one-electron reactions.

In his work, Foote ${ }^{1 \mathrm{c}}$ generally uses ${ }^{1} \mathrm{O}_{2}$ that is produced when sodium hypochlorite is treated with hydrogen peroxide. In this reaction chloroperoxy anion is formed, then decomposed to give ${ }^{1} \mathrm{O}_{2}$ and chloride ion. 


\begin{tabular}{|c|c|c|}
\hline States of molecular oxygen & $\begin{array}{l}\text { Electron } \\
\text { distribution }\end{array}$ & $\begin{array}{l}\text { Energy above } \\
\text { ground state }\end{array}$ \\
\hline $\begin{array}{l}\text { Second excited state }\left({ }^{1} \Sigma_{g}^{+}\right) \\
\text {First excited state }\left({ }^{1} \Delta_{g}\right) \\
\text { Ground state }\left({ }^{3} \Sigma_{g}^{-}\right)\end{array}$ & $\begin{array}{ll}\uparrow & \downarrow \\
\uparrow \downarrow & + \\
\uparrow & \uparrow\end{array}$ & $\begin{array}{l}37 \mathrm{kcal} \\
22 \mathrm{kcal}\end{array}$ \\
\hline
\end{tabular}

Figure 2. States of molecular oxygen, their energy levels and the electron distribution in the highest occupied orbitals

$$
\begin{aligned}
\mathrm{H}_{2} \mathrm{O}_{2}+{ }^{\ominus} \mathrm{OCl} & \rightarrow{ }^{\ominus} \mathrm{O}_{2} \mathrm{Cl} \\
{ }^{\ominus} \mathrm{O}_{2} \mathrm{Cl} & \rightarrow{ }^{1} \mathrm{O}_{2}+\mathrm{Cl}^{\ominus}
\end{aligned}
$$

The ozone adducts of aryl phosphites decompose thermally with the formation of $\mathrm{O}_{2}$ and aryl phosphates. This observation made by Murray and $\mathrm{Kaplan}^{6}$ was exploited in preparative organic chemistry, in particular by Schaap and Bartlett ${ }^{2}$.

$$
\left(\mathrm{C}_{6} \mathrm{H}_{5} \mathrm{O}\right)_{3} \mathrm{P}+\mathrm{O}_{3} \stackrel{-78 \mathrm{C}}{\longrightarrow}\left(\mathrm{C}_{6} \mathrm{H}_{5} \mathrm{O}\right)_{3} \mathrm{P}
$$

A third method, developed furthest by Schenck and his collaborators, is the photochemical dye-sensitized generation of ${ }^{1} \mathrm{O}_{2}{ }^{1 a}$ from ground state oxygen $\left({ }^{3} \mathrm{O}_{2}\right)$. According to the Kautsky mechanism ${ }^{7}$, energy transfer from the triplet state of sensitizer to triplet oxygen $\left({ }^{3} \mathrm{O}_{2}\right)$ occurs with formation of ${ }^{1} \mathrm{O}_{2}$ and ${ }^{1} \mathrm{Sens}_{0}$. The triplet sensitizer is produced from a dye in the first excited singlet state by an intersystem crossing process. Finally the electronic excitation of a dye is induced by light. Reactions with the ${ }^{1} \mathrm{O}_{2}$ obtained in this way are thus also termed dye-sensitized photo-oxygenation reactions. All of our work was performed with photochemically produced ${ }^{1} \mathrm{O}_{2}$.

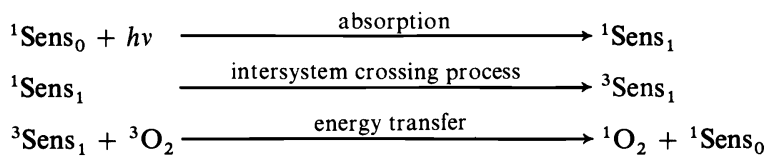

The sensitizers usually applied are dyes either of the porphyrin group, such as hematoporphyrin with a triplet energy $\left(E_{t}\right)$ of $38 \mathrm{kcal} \mathrm{mol}^{-1}$, or of the xanthen group in a zwitterionic form, such as fluorescein $\left(E_{\mathrm{t}}=46 \mathrm{kcal}\right.$ $\left.\mathrm{mol}^{-1}\right)$ and rose bengal $\left(E_{\mathrm{t}}=40 \mathrm{kcal} \mathrm{mol}^{-1}\right)$. Methylene blue $\left(E_{\mathrm{t}}=34 \mathrm{kcal}\right.$ $\mathrm{mol}^{-1}$ ) is also often used.

\section{1,4-ENDOPEROXIDES AS REACTIVE INTERMEDIATES}

Primary products of photo-oxygenation are not useful as such. The low 


\section{G. OHLOFF}

chemical stability of the peroxides can, however, take advantage of selective transformations giving important compounds.

The only exception is Ascaridole (8). This bridged peroxide was also the first example of the use of ${ }^{1} \mathrm{O}_{2}$ in preparative organic chemistry provided by Schenck and Ziegler ${ }^{8}$. The 1,3-diene system of $\alpha$-terpenene (7) adds just one mole of ${ }^{1} \mathrm{O}_{2}$, with practically quantitative formation of their 1,4endoperoxide 8 (Figure 3). Ascaridole (8) is the pharmacologically active principle of the oil of American wormseed and its synthetic equivalent prepared in this way was used in the 1950 s as a remedy against mawworm.<smiles>CC1=CC=C(C(C)C)CC1</smiles>

7

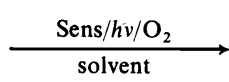

Figure 3. Dye-sensitized photo-oxygenation of $\alpha$-terpenene (7). Synthesis of ( \pm )-Ascaridole (8)

Hitherto, the chemistry of 1,4-endoperoxides has been little developed. The best known reaction is the Kornblum reaction ${ }^{9}$, which takes place under nucleophilic conditions with 1,2-dioxolan derivatives having a secondary peroxy group. Interesting examples can be derived from the formation of hydroxycarbonyl compounds 17,39 and 49.

The reaction involving the use of the Horner reagent ${ }^{10}$ has been investigated more particularly with Ascaridole (8) (Figure 4). In the presence of triphenylphospine, 8 yields, besides 1,4 -epoxide $(9)^{10}, \Delta^{2}$-p-menthene-4-ol (10) and as the main product 1,2-epoxy compound $(11)^{11}$.

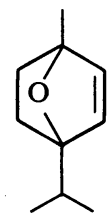

9

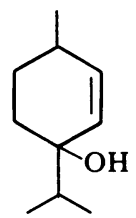

10

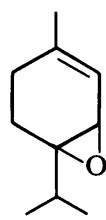

11

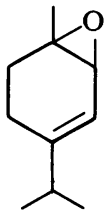

12

Figure 4. Treatment of Ascaridole (8) with $\mathrm{P}(\mathrm{Ph})_{3}$

The epoxides 9, 11 and 12 are monoterpene derivatives which were not accessible up to now. The diastereoisomeric allylic alcohols (10) have already been obtained by photo-oxygenation of $[+]-\Delta^{3}-p$-menthene ${ }^{12}$. The heterolytic cleavage of the peroxy bond according to model A yields an ion pair B which forms 9 by a 1,4-elimination or 11 by a corresponding vinylogous process. The attack of the phosphine on the oxygen of the isopropyl group in 8 should also yield 9 besides 12. Actually, 1,2-epoxy- $\Delta^{3}$-p-menthene (12) was found among the reaction products resulting from $\mathbf{8}^{11}$.

According to Schenck and Dunlap ${ }^{13}$, the 1,3-diene system in a fivemembered ring (13) reacts with ${ }^{1} \mathrm{O}_{2}$ in the same way as a 1,3-diene system in 

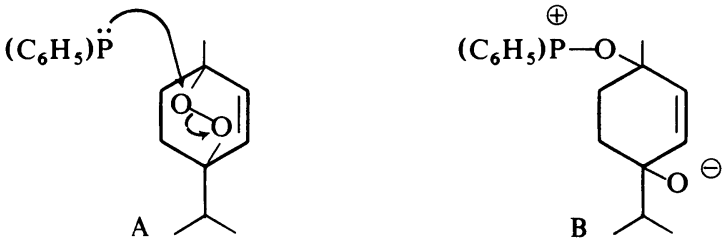

a six-membered ring (Figure 5). As we have found ${ }^{14}$, the 1,2-dioxolane derivative (14), which can be isolated in crystalline form at $-100^{\circ} \mathrm{C}$, is rapidly converted to a great extent to 4,5 -epoxy-cis-pentenal (15) at $-20^{\circ} \mathrm{C}$ under neutral conditions. In this reaction a small amount of the cis-diepoxide (16) of cyclopentadiene (13) is also formed. In the presence of a weak base, the Kornblum-DeLaMare reaction ${ }^{9}$ takes place to give 20 per cent 1 -hydroxycyclopent-2-en-4-one (17).

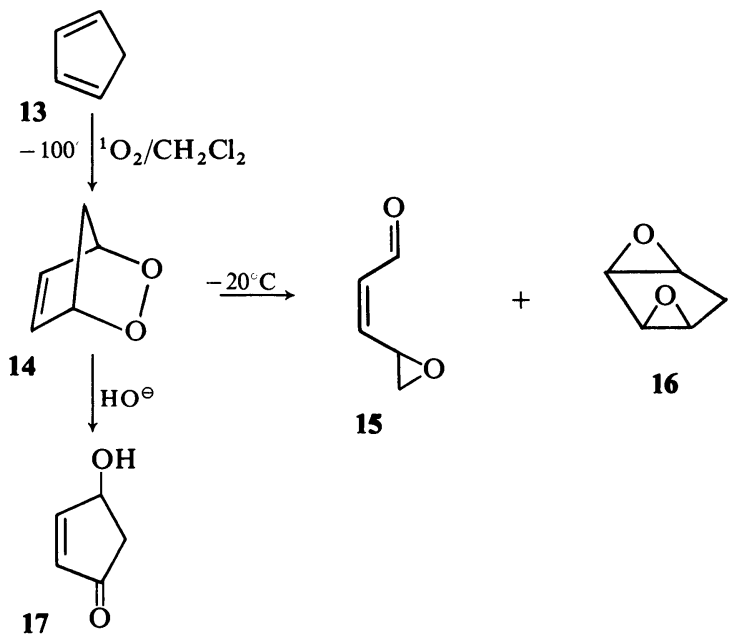

Figure 5. Dye-sensitized photo-oxygenation of cyclopentadiene (13). Formation of 4,5-epoxycis-2-pentenal (15)

In the presence of triphenyl phosphine in benzene at room temperature smooth and quantitative cis-trans isomerization $(15 \rightarrow 18)$ of the double bond occurred ${ }^{14}$ (Figure 6).

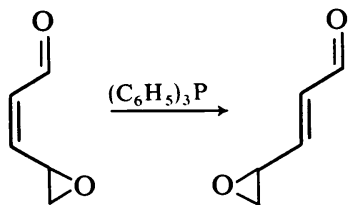

15

18

Figure 6. Cis-trans isomerization of 4, 5-epoxy-cis-pentenal (15) 


\section{G. OHLOFF}

In the course of our investigations, epoxypentenal was shown to be an extremely interesting species. Thus 15 and 18 proved to be versatile dienophiles ${ }^{14,15}$. As an example (Figure 7), compound 20, the Diels-Alder adduct of 18 to isoprene (19), rearranges easily to form the bicyclic dihydrofurfuryl alcohol (21) ${ }^{16}$.

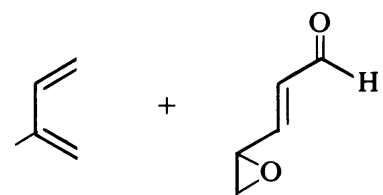

19

18<smiles>CC1=CCC(C=O)C(C2CO2)C1</smiles>

20<smiles>OCC1OC=C2CC=CCC21</smiles>

21

Figure 7. Diels-Alder reaction of 4,5-epoxy-trans-2-pentenal (18) with isoprene (19). Formation of dihydrofurfuryl alcohol derivative (21).

With hexyl triphenyl phosphonium chloride, under the conditions described by Schlosser ${ }^{17}$, trans-epoxypentenal (18) undergoes a clean Wittig condensation with the introduction of the desired cis-double bond (Figure 8 ) to give 22. Subsequent treatment with periodic acid gave the decadienal 23 having one carbon atom less, and this was finally converted, by the method of Corey, with manganese dioxide into the ethyl ester of 2-trans, 4-cis-decadienoate $(\mathbf{2 4})^{18}$. This compound occurs in nature and represents the odorant principle of the Bartlett pear ${ }^{19}$.

On the other hand, 2-trans, 4-cis-decadienal (23) reacts with methyl triphenyl phosphonium chloride to give the 1,3-trans, 5-cis-undecatriene (25) (Figure 8) ${ }^{20}$, one of the known stereoisomers of galbanolene, a natural constituent of the odoriferous principle of galbanum ${ }^{21}$. 2,4-Dienals with $7-12$ carbon atoms are already important flavour components and contribute essentially to meat flavour. They can be synthesized like decadienal (Figure 8 ) by using the homologous Wittig reagent with an aliphatic chain of 3-8 C-atoms.

The monomethyl derivatives of cyclopentadiene behave in a similar manner (Figure 9). After photo-oxygenation of the 1,3-dienes 26, 27 and 28 which were present in an equilibrium, the unsaturated epoxyaldehydes 32 35 were isolated from the reaction mixture ${ }^{22}$. They form from the corresponding 1,2-dioxolans 29,30 and 31, which rearrange already at low temperatures, as does the parent compound (14). It is obvious that epoxyaldehydes 32-35 represent valuable building units for syntheses. 


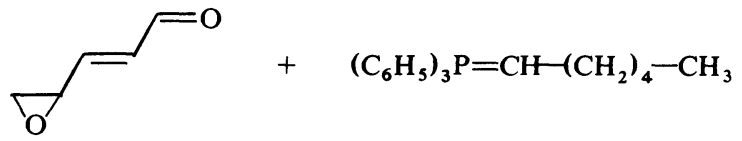

18

$$
\text { (87\%) }
$$

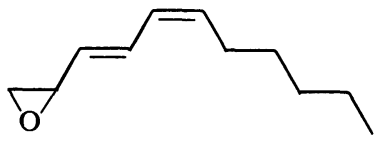

22

$$
(96 \%) \downarrow \mathrm{H}_{5} \mathrm{O}_{6}
$$

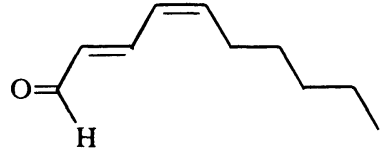

23

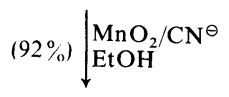

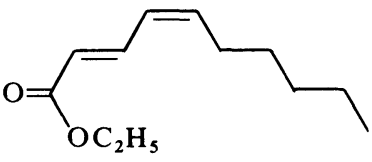

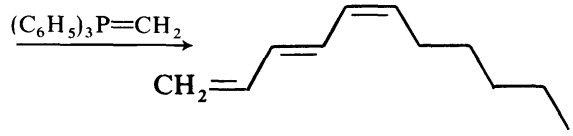

25

24

Figure 8. Synthesis of ethyl-2-trans, 4-cis-decadienoate (24) (pear ester) via 4,5-epoxy-trans-2pentenal (18)

Differing from cyclopentadiene (13) and its methyl homologues 26-28, 6,6-dimethyl fulvene (36), when subjected to photo-oxygenation (Figure 10) in a neutral medium, yields mainly lastone 37 besides the two cyclopentane derivatives 38 and $39^{23}$.

In polar or better in basic solvents the Kornblum-DeLaMare reaction ${ }^{9}$ preferentially takes place and leads mainly to 39. By analogy with the rearrangement of 14, it was assumed that a corresponding 1,2-dioxolan derivative (40) first yields a labile allene-epoxy derivative (41) (Figure 11) which further reacts through $\mathbf{4 2}$ to finally yield lactone 37 as a stable end product $^{23,24}$. A synchronous transformation of $\mathbf{4 0}$ to 37 was also considered possible ${ }^{25}$.

Lactone (37) possesses a remarkable property. It undergoes a thermally induced fragmentation reaction which results almost exclusively in the formation of 5-methyl-hexadienal (43) and $\mathrm{CO}$. This reaction takes place in a concerted manner and, according to Woodward and Hoffmann ${ }^{26}$, belongs to the group of cheletropic reactions. The aldehyde (46) is formed correspondingly from lactone $4 \dot{4}$, which in turn is formed by photo-oxygena- 


\section{G. OHLOFF}<smiles>CC1=CC=CC1</smiles>

26

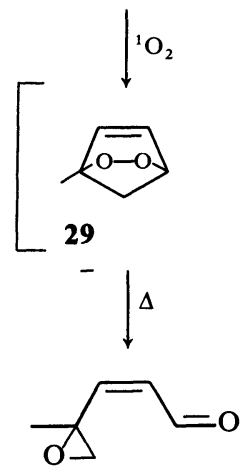

32<smiles>CC1=CCC=C1</smiles>

27

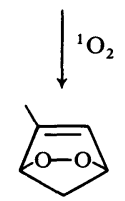

30

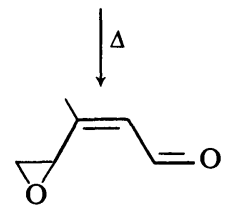

$33+$<smiles>C/C(C=O)=C/C1CO1</smiles>

35

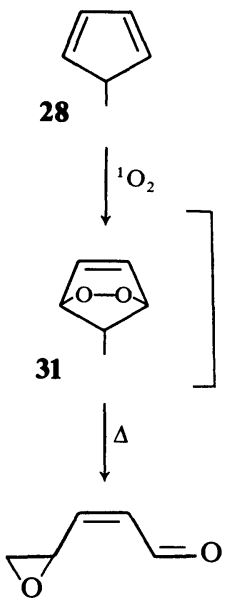

34

Figure 9. Dye-sensitized photo-oxygenation of methylcylopentadienes 26-28. Formation of different methyl-4,5-epoxy-cis-2-pentenals 32-35<smiles>CC(C)=C1C=CC=C1</smiles>

36<smiles>CC1(C)C=CC=COC1=O</smiles>

37<smiles>CC(C)=C1C(=O)C=CC1O</smiles>

39

Figure 10. Dye-sensitized photo-oxygenation of 6,6-dimethyl fulvene (36)<smiles>CC(C)=C1C2C=CC1O2</smiles>

40

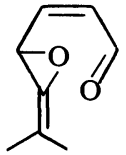

41

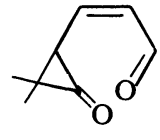

42

Figure 11. Formation of lactone 37 from endoperoxide (40)<smiles>CC(C)=CC=CC=O</smiles> 
<smiles>CC(=C1C=CC=C1)c1ccccc1</smiles>

44

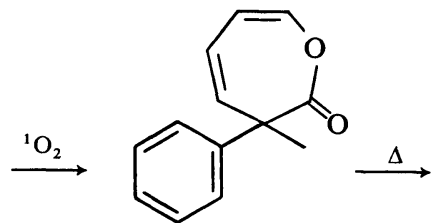

45<smiles>C/C(=C\C=C\C=O)c1ccccc1</smiles>

46

Figure 12. Dye-sensitized photo-oxygenation of 6-methyl, 6-phenyl fulvene (44)

tion of fulvene derivative $44^{27}$ (Figure 12). Variation of the fulvene structure leads to a general preparative method for preparing 2,4-diene-carbonyl compounds which are difficult to obtain by other means.

Nopadiene $^{28}$ and $1,1^{\prime}$-bicyclohexenyl ${ }^{29}$ are the sole compounds having a mobile 1,3-diene system with which a [4+2] cyclo-addition of ${ }^{1} \mathrm{O}_{2}$ was observed. However, the preparative possibilities of a novel furan synthesis starting from these endoperoxides were already recognized at that time. This transition seems to have a biochemical relevance as well, as the investigations of Demole et al. ${ }^{30}$ suggest, since it was possible to make a link between the two natural products solanone $(\mathbf{4 7})^{31}$ and solanofuran $(\mathbf{5 0})^{30}$ found in tobacco via a diene synthesis with ${ }^{1} \mathrm{O}_{2}$ in vitro (Figure 13). Indeed, the photooxygenation of 47 resulted in a 36 per cent yield of 1,2-diox-4-ene (48), which underwent a Kornblum-DeLaMare rearrangement on basic $\mathrm{Al}_{2} \mathrm{O}_{3}$ and yielded directly solanofuran (50) via the hydroxyaldehyde or its hemiacetal (49).<smiles>C=C(C)/C=C/C(CCC(C)=O)C(C)C</smiles>

47

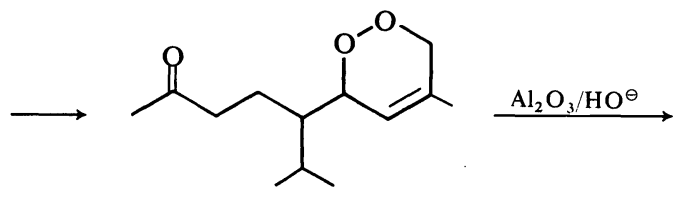

48<smiles>C#CC(=O)CCC(C(C)C)C(/C=C(/C)C(=O)O)OC(O)/C(C)=C\C(O)C(CCC(C)=O)C(C)C</smiles>

49

50

Figure 13. Dye-sensitized photo-oxygenation of solanone (47). Formation of solanofuran (50) via the corresponding 1,2-diox-4-ene (48)

Furthermore, most recently it was also possible to prepare substituted 3,6-dihydro-o-dioxins by photo-oxygenation of simple acyclic 1,3-dienes such as isoprene ${ }^{32}$.

The acceptor system of furans is closely related to that of cyclopentadiene (13). However, the endoperoxide that is formed behaves very differently. According to Foot et al. ${ }^{33}$, 2,5-dimethylfuran (51) takes up one mole of 


\section{G. OHLOFF}

${ }^{1} \mathrm{O}_{2}$ by way of a $[4+2]$ cyclo-addition. This endoperoxide (52) can be viewed as a mono-ozonide of 1,2-dimethyl cyclobutadiene. It is, therefore, an extremely reactive species. If methanol is used as solvent, nucleophilic addition gives the methoxy hydroperoxide (53) which is stable up to $100^{\circ} \mathrm{C}$ (Figure 14).

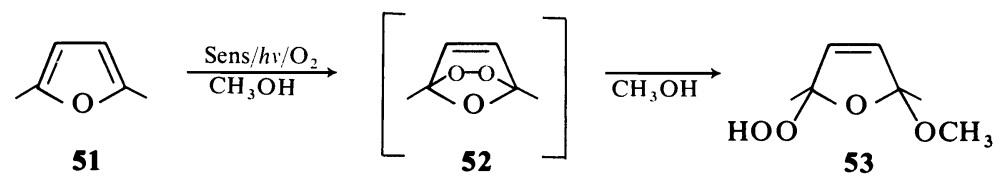

Figure 14. Dye-sensitized photo-oxygenation of 2,5-dimethylfuran (51) in methanol

However, if the photo-oxygenation of 2,5-dimethylfuran (51) is carried out in a non-polar solvent such as $\mathrm{CH}_{2} \mathrm{Cl}_{2}$ or benzene (Figure 15), then at room<smiles></smiles>

52

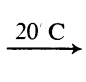<smiles></smiles>

54<smiles>CC(=O)/C=C/C(C)=O</smiles>

55

Figure 15. Thermally induced reaction of 2,5-dimethylfuran endoperoxide (52)

temperature a dimeric ozonide 54 which sublimes at $120^{\circ} \mathrm{C}$ and melts without decompsosing at $154^{\circ} \mathrm{C}$ is formed from the endoperoxide $\mathbf{5 2}^{29}$. In the gas phase above $180^{\circ} \mathrm{C}$ the dimeric ozonide 54 breaks down and gives as a stable end-product the dione $\mathbf{5 5}^{16}$.

According to the reaction diagram in Figure 14, the lower homologue of 51, i.e. 2-methylfuran, gives with ${ }^{1} \mathrm{O}_{2}$ in 80 per cent yield a crystalline reaction product 56 having exclusively a secondary hydroperoxy group ${ }^{33}$.

On the other hand, the unsubstituted furan, when photo-oxygenated in methanol, yields the peroxide-free product $57^{34}$, the pseudo-ester of maleic aldehyde acid.<smiles>COC1(C)C=CC(O)O1</smiles>

56<smiles>COC1C=CC(=O)O1</smiles>

57

The chemistry of the products obtained by photo-oxygenation of furans is particularly interesting, in so far as these products lead to important poly-functional building units for syntheses, i.e. reactive compounds which are difficultly accessible or even not accessible at all by other means (Figure 16). In the presence of triphenylphosphine, 53 can be converted into 3-transhexene-2,5-dione (55) in a yield of 90 per cent, whereas 56 yields $\beta$-acetyl- 
acrolein (58) in this reaction ${ }^{33}$. As already mentioned, $\mathbf{5 5}$ is also obtained as the sole product of the pyrolysis of the dimeric ozonide 54 at $180^{\circ} \mathrm{C}^{35}$.<smiles>CC(=O)/C=C/C(C)=O</smiles>

55<smiles>O=C/C=C\C(=O)O</smiles>

60<smiles>CC(=O)/C=C/C=O</smiles><smiles>O=C1C=CC(O)O1</smiles>

61<smiles>CC(=O)/C=C/C(=O)O</smiles><smiles>O=C/C=C/C(=O)O</smiles>

62

Figure 16. Building units for syntheses obtained by photo-oxygenation of furans

The action of alkali on methoxy-hydroperoxide 56 results in the formation of $\beta$-acetylacrylic acid (59) in a yield of 80 per cent $^{33}$. On the other hand, the treatment of 57 with dilute mineral acids yields maleic aldehyde acid (60). and its pseudo-form (61), respectively, both being present in an equilibrium, whereas strong acids convert 57 directly into fumaric aldehyde acid $(62)^{36}$.

\section{SYNTHETIC USE OF ALLYL-HYDROPEROXIDES}

At this point I should like to leave the Diels-Alder reaction with ${ }^{1} \mathrm{O}_{2}$ and turn to the possible uses which ene-reactions with ${ }^{1} \mathrm{O}_{2}$ offer the organic chemist who is engaged in synthesizing naturally occurring products.

As indicated in Figure 1 (case $\mathrm{C}$ ), ${ }^{1} \mathrm{O}_{2}$ reacts with unconjugated double bonds in an ene-type reaction to form allylic hydroperoxides. The rate of this reaction increases with the degree of substitution of the double bond.

This fact can be illustrated by the behaviour of limonene (63) on photooxygenation ${ }^{5}$ (Figure 17). One mole of ${ }^{1} \mathrm{O}_{2}$ is rapidly consumed and it is exclusively the trisubstituted double bond that is attacked. After reduction of the initially formed mixture of the allyl hydroperoxides with $\mathrm{CH}_{3} \mathrm{SCH}_{3}$ or $\mathrm{Na}_{2} \mathrm{SO}_{3}$, six corresponding allylic alcohols (64-69) were isolated which constituted three diastereoisomeric pairs. The difference between the photooxygenation and the autoxidation of limonene (63) is evident, not only from the differences in the product distribution that were found, but also from the fact that the diastereoisomeric carveols (68 and 69) produced by dyesensitized photo-oxygenation are formed with 100 per cent optical yield, while the same products from autoxidation are racemates ${ }^{37}$. Hence, it was possible to demonstrate that the addition of singlet oxygen to the acceptor system and the abstraction of hydrogen in photo-oxygenation must be in a concerted process ${ }^{1 \mathrm{c}, 5}$, whereas in the case of autoxidation a symmetrical intermediate must be passed through ${ }^{37}:$ in other words, autoxidation follows a radical mechanism. 


\section{G. OHLOFF}
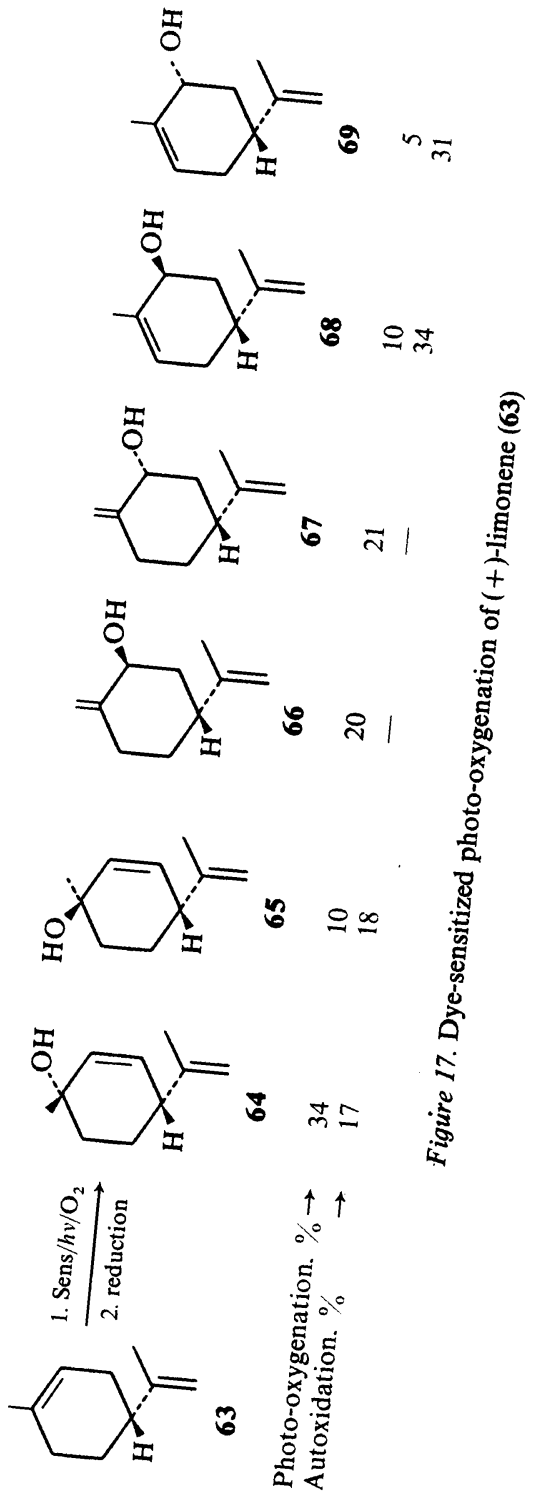
All six allylic alcohols (64-69) formed in this reaction occur in nature ${ }^{38}$. Separated by fractional distillation, these alcohols constitute readily accessible starting compounds for a series of interesting monoterpene derivatives. Thus, when heated at $230^{\circ} \mathrm{C}$ in a closed vessel, the axial acetate (70) of the enantiomer of 66 rearranges into perilla acetate (71) in a yield of about 80 per cent, wheras the equatorial derivative (72) gives only 15 per cent of 71 in the same reaction ${ }^{39}$ (Figure 18). The major quantity thereof is converted into $p$-cymol (73) (75 per cent) by ester pyrolysis.<smiles>C=C(C)C1CCC(=C)C(OC(C)=O)C1</smiles>

70<smiles>C=C(C)C1CCC(=O)[C@H](OC(C)=O)C1</smiles>

72
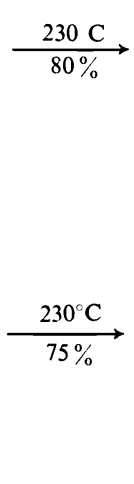

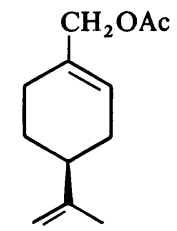

71

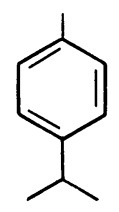

73

Figure 18. Thermal treatment of the diastereoisomeric 2-acetoxy- $\Delta^{1(7), 8}-p$-menthadiene

The readily acid-catalysed allylic rearrangement of the two tertiary (64 and 65) alcohols was exploited in synthesizing pharmacologically active constituents of marihuana (Figure 19).

When a mixture of the diastereoisomers 64 and 65 and olivetol (66) is heated in benzene in the presence of $p$-toluene sulphonic acid, $(-)-\Delta^{8}$-transtetrahydrocannabinol (69) is formed directly in one step, in 50 per cent yield. We presume that the secondary allylic carbonium ion A formed from the tertiary allylic alcohols (64 and 65) reacts as an electrophile with the resorcinol derivatives 66 in a kind of electrophilic substitution reaction. This first gives rise to (-)-cannabidiol (67). One of the two phenolic hydroxyl groups immediately reacts further with the isopropenyl double bond with the formation of an ether, and in addition the $\Delta^{9}$-double bond in the trans-tetrahydrocannabinol (68) is transferred into the thermodynamically more stable $\Delta^{8}$ position (69). Finally, we were able to convert the psychotropically inactive $\Delta^{8}$-compound 69 quantitatively into the active $\Delta^{9}$-compound $(68)$ by treating its common mono-chlorohydrate with Na-tert-amylate. At present, this synthesis is probably the simplest route to the active principle of hashish ${ }^{40}$.

The so-called laevorotatory rose oxide which was discovered by Seidel and Stoll ${ }^{41}$ represents an important component of Bulgarian rose oil. It occurs in two diastereoisomeric forms (73 and 74) and is a monoterpene with a tetrahydropyran structure ${ }^{42}$. The formation of this cyclic ether (Figure 20) 


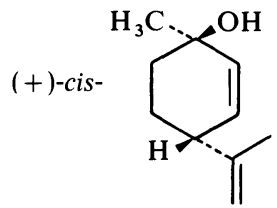<smiles>C=C(C)C1CCCC1C(C)C</smiles>

65

64
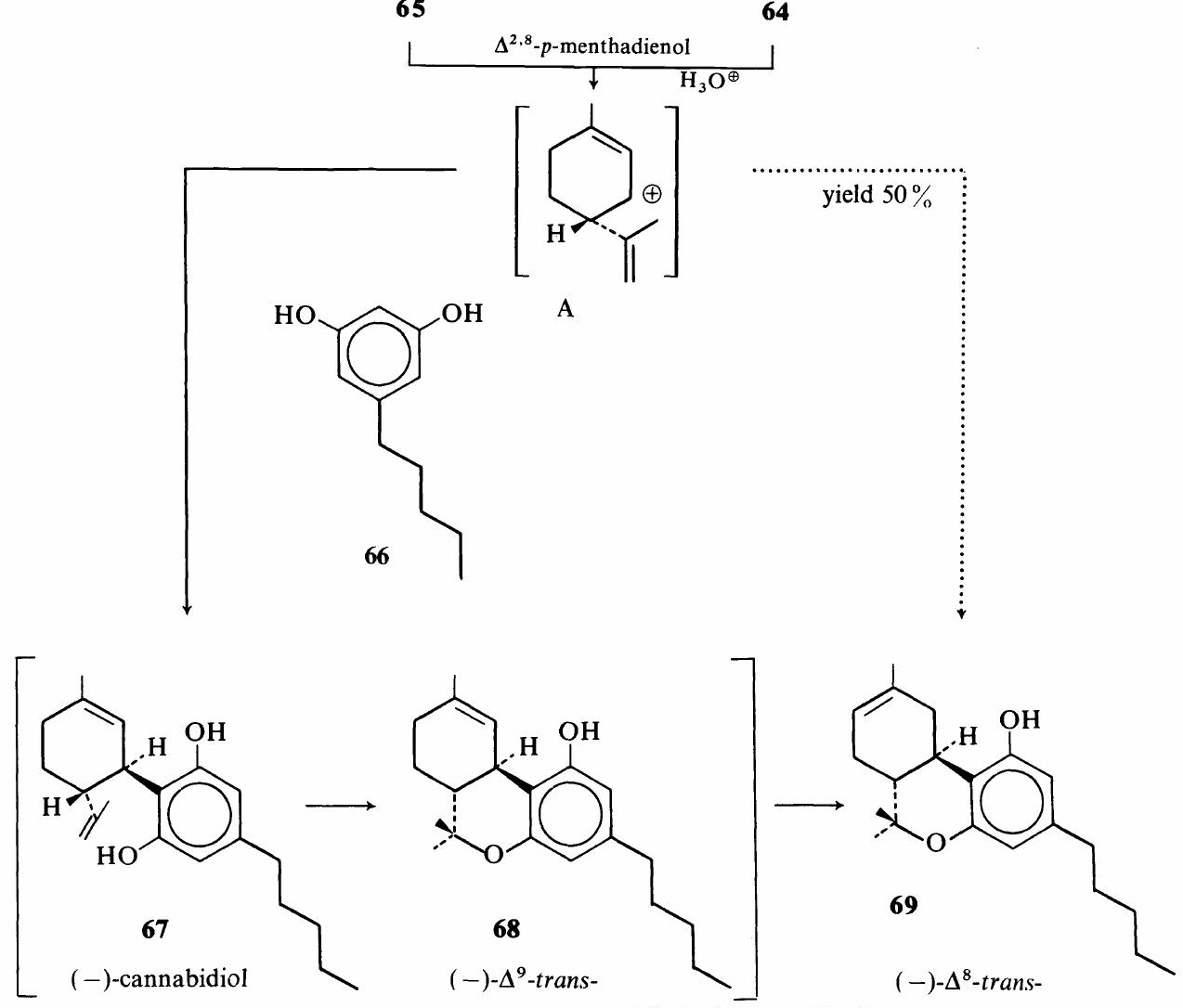

tetrahydrocannabinal

Figure 19. Synthesis of (-)- $\Delta^{9}$-trans-tetrahydrocannabinol (68) (THC), the psychotropic principle of hashish

follows a sequence of reactions similar to the one used for the synthesis of $(-)-\Delta^{8}$-THC (69) (Figure 19). (-)-Citronellol (70), which is also present in rose oil, is used as a synthetic precursor. On treatment with dye-sensitized oxygen it yields almost quantitatively two isomeric h-droxy allyl hydroperoxides, which result from ene-reaction with the double bond. After reduction of the hydroperoxy group with $\mathrm{Na}_{2} \mathrm{SO}_{3}$ in methanol, and subsequent acidification with dilute mineral acid, a 60 per cent yield of the diastereoisomeric rose oxides (73 and 74) in a ratio of about $1: 1$ is obtained ${ }^{43}$. It is only the tertiary allylic alcohol (71) produced in a 60 per cent yield which 
SINGLET OXYGEN: A REAGENT IN ORGANIC SYNTHESIS

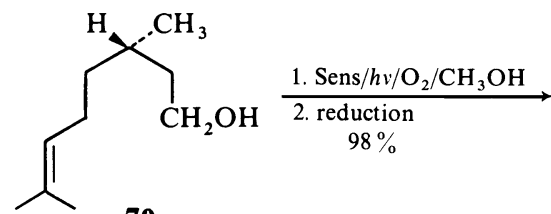

70

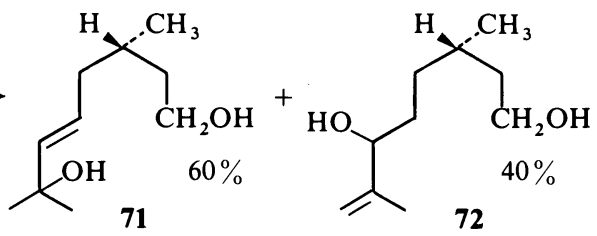

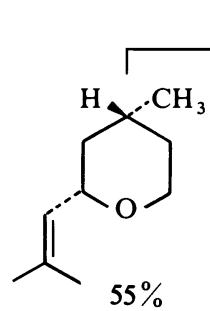

73

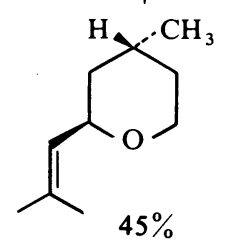

74

Figure 20. Dye-sensitized photo-oxygenation of (-)-citronellol (70). Process of preparation of the diastereomers of $(-)$-rose oxide (73 and 74)

under these conditions is transformed into the diastereoisomeric tetrahydropyran compounds, while the secondary allylic alcohol (72) remains unchanged. It is estimated that about two tons of ${ }^{1} \mathrm{O}_{2}$ per year are being used today to cover the demand for rose oxide which is produced by this method.

Since E. Demole has recently succeeded in isolating the secondaryprimary diol (72) from Bulgarian rose oil in our laboratory ${ }^{44}$, we believe that the biogenetic route must be very similar to the synthetic route shown in Figure 20.

Besides rose oxide (73 and 74), $\beta$-damascenone (83) represents the other equally important fragrance which was isolated for the first time in our laboratory from Bulgarian rose oil and which jointly represent the odorant principle of this costly essential oil ${ }^{45}$. Both odoriferous substances now have become accessible on an industrial scale from corresponding precursors via ${ }^{1} \mathrm{O}_{2}$ reactions.

As we found, $\beta$-damascol (75), which is easily accessible by a Grignard reaction from propenyl magnesium bromide and $\beta$-cyclo-citral on treatment with ${ }^{1} \mathrm{O}_{2}$, is transformed in good yield into a $3: 2$ mixture of the corresponding $\alpha, \beta$-epoxy ketone (78) and an $\alpha$-methylene ketone (79), along with crotonaldehyde (80) (Figure 21). The ${ }^{1} \mathrm{O}_{2}$ is thus chiefly added at the lower end of the double bond of $\beta$-damascol (75) with the simultaneous abstraction of the allylic hydrogen on the carbon atom of the hydroxyl group. The enol hydroperoxide (76) thus formed stabilizes by intramolecular dehydration with the formation of the epoxy ketone (78) ${ }^{46}$. The formation of epoxy ketones from allylic alcohols with ${ }^{1} \mathrm{O}_{2}$ has hitherto been found only in the case of $\Delta^{4}$ cholesterol by Nickon and Mendelson ${ }^{47}$ as a minor reaction and further investigated by Foote ${ }^{48}$ on related model compounds.

For steric reasons access of ${ }^{1} \mathrm{O}_{2}$ to the upper end of the double bond is difficult, so that the yield of the $\alpha$-hydroxy hydroperoxide (77) reaches only 
G. OHLOFF<smiles>C/C=C/C(O)C1=C(C)CCCC1(C)C</smiles>

75

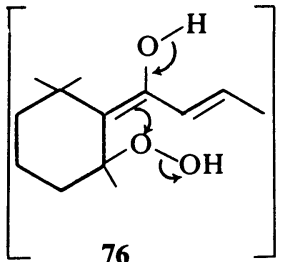

$\overrightarrow{60 \%}$<smiles>C/C=C/C(=O)C12OC1(C)CCCC2(C)C</smiles>

78<smiles>C=C1CCCC2(C)COOC1(/C=C/C)OO2</smiles>

77<smiles></smiles>

79

Figure 21. Dye-sensitized photo-oxygenation of $\beta$-damascol (75)

40 per cent. The compound is stable at about $0^{\circ} \mathrm{C}$. Above room temperature, or faster in the presence of an acid, a fragmentation reaction sets in. $\alpha$ Hydroxy hydroperoxides thus exhibit an analogous behaviour to $\alpha$-hydroxy ozonides.

In the presence of dilute hydrochloric acid in dioxan, the opoxy group of 78 opens at $60^{\circ} \mathrm{C}$ to give the allylic alcohols 81 and 82, which in turn are dehydrated at $100^{\circ} \mathrm{C}$, giving $\beta$-damascenone (83) (Figure 22). $\beta$-Damascenone (83) is also formed in one step and in 80 per cent yield, if the epoxy ketone (78) is treated directly at $100^{\circ} \mathrm{C}(\mathrm{A}$, Figure 19$)$.<smiles>C=C1CCCC(C)(C)C1(O)C(=O)/C=C/C</smiles>

81<smiles>C/C=C/C(=O)C12CC(C)(CCCC1(C)C)O2</smiles><smiles>CC(C)[GeH3]</smiles><smiles>[C+]=C</smiles>

78<smiles>CC1=CCCC(C)(C)C1(O)C(=O)/C=C/[C@H](C)Cl</smiles>

82<smiles>CC=CC(=O)C1=C(C)C=CCC1(C)C</smiles>

83

Figure 22. Acid-catalysed formation of $\beta$-damascenone (83) from 5,6-epoxy-dihydro-damascone 
The fragmentation reaction of $\alpha$-hydroxy-hydroperoxides can be applied specifically to the synthesis of carbonyl compounds (Figure 23) ${ }^{49}$. The versatility of this method resides in the fact that the substituents $R$ and $R^{\prime}$ in the desired product 87 can be predetermined by a corresponding Grignard reaction from 84 to 85 . The allylic alcohol (85), especially if it is a tertiary carbinol, has no other possibility than to form 86 in the presence of ${ }^{1} \mathrm{O}_{2}$.<smiles>[R]C(=O)C=C(C)C</smiles>

84

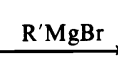<smiles>[R]C([R])(O)C=C(C)C</smiles>

85<smiles>[R]C([R])(O)C(OO)C(=C)C</smiles>

86
87<smiles>[R]C([R])=O</smiles>

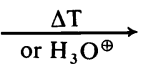<smiles>C=C(C)C=O</smiles>

88

Figure 23. Formation and fragmentation of $\alpha$-hydroxy-hydroperoxides (86)

This method of synthesis is particularly mild since the $\alpha$-hydroxy-hydroperoxides (86) decompose already at temperatures slightly above room temperature or in the cold to form components $\mathbf{8 7}$ and $\mathbf{8 8}$.

The next two examples show that only the rearrangement of the allylic alcohols can be used for synthetic purposes; in special cases, a similar allylic rearrangement can be carried on the allylic hydroperoxides themselves. In the presence of catalytic amounts of copper (I) salts, the diastereoisomeric 1-hydroperoxy- $\Delta^{2,8(9)}$ - $p$-menthadienes (89) rearrange to give the corresponding secondary hydroperoxides (90), which are then transformed into optically active piperitenone (91), by $\alpha$-elimination of a molecule of water ${ }^{5}$ (Figure 24).

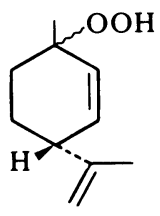

89

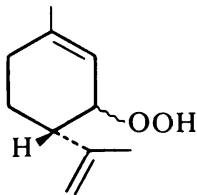

90

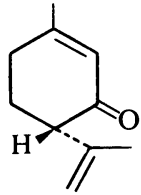

91

Figure 24. Copper (I)-catalysed rearrangement of 1-hydroperoxy- $\Delta^{2,8(9)}$-p-menthadienes (89)

In the same way, $(+)$-nootkatone $(97)$ is formed from the tertiary allylic hydroperoxide (93) derived from $(+)$-valencene $(92)(\text { Figure } 25)^{50}$. The tertiary peroxide (93) is the main product of the dye-sensitized photooxygenation of 92. At room temperature it rearranges spontaneously. The secondary allylic hydroperoxide (94), which is found as a side product, is stable under these conditions. In the absence of copper (I) ions in the reaction mixture, the reaction ends with the formation of the secondary allylic hydroperoxides (95 and 96). 


\section{G. OHLOFF}

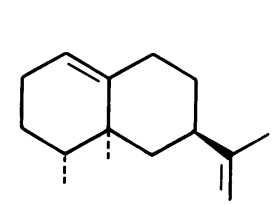

92

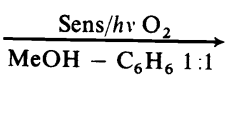

(23\%)

95<smiles>C=C(C)[C@@H]1CC[C@@]2(O)C=CCC(C)C2(C)C1</smiles>

$72 \%$<smiles>C=C(C)[C@@H]1CC=C2C(O)CCC(C)C2(C)C1</smiles>

94

$48 \mathrm{~h}$

$(<95 \%)$

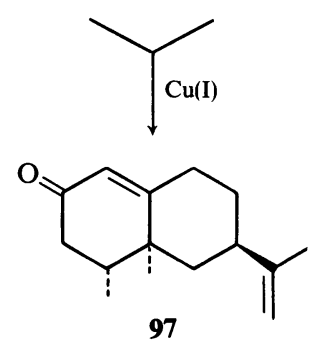

96

Figure 25. Dye-sensitized photo-oxygenation of $(+)$-valencene (92) and formation of $(+)$ nootkatone (97)

In the case of valencene (92), under the conditions used, ${ }^{1} \mathrm{O}_{2}$ reacts almost exclusively with the trisubstituted double bond. In contrast, the double bond of the isopropylidene side chain of isovalencene (98) is photo-oxygenated much more rapidly, with formation of a mixture of the diastereoisomeric tertiary allylic hydroperoxides (99) (Figure 26). In the presence of borontri-<smiles>CC(C)=C1CCC2=CCCC(C)C2(C)C1</smiles>

98

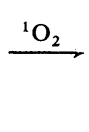

(1)

Figure 26. Dye-sensitized photo-oxygenation of $(+)$-isovalencene (98). Formation of $(+)-1$, 10-dimethylbicyclo [4. 4. 0] dec-6-en-3-one (100) via a fragmentation reaction of 7-hydroperoxy valencene (99)

fluoride etherate these hydroperoxides undergo a fragmentation reaction, which leads to the formation of the octalone derivative (100). This material has been isolated from Reunion Vetiver Oil (Vetiveria zizanoides L.). The over-all yield of this transformation $(\mathbf{9 8} \rightarrow \mathbf{1 0 0})$ is better than 90 per cent $^{51}$.

The fragmentation step is essentially a Hock cleavage ${ }^{52}$, which occurs via 
the mechanism proposed by Criegee ${ }^{53}$. It has also been used in a novel synthesis of exaltone ${ }^{54}$, and to prepare (-)-geijerone $(\mathbf{1 0 5})^{55}$, which has been isolated from juniper oil (Juniperus communis L.). The latter synthesis involves photo-oxygenation of $(+)-\gamma$-elemene (101). Of the three double bonds available, only the tetrasubstituted one reacts efficiently with ${ }^{1} \mathrm{O}_{2}$ (Figure 27). Three hydroperoxides (102-104) are formed; their structure was determined by converting them to the corresponding allyl alcohols. All three hydroperoxides, on treatment with borontrifluoride etherate or with protic acids, are transformed into the same ketone $(\mathbf{1 0 5})^{56}$. We think that the formation of sesquiterpenoid $\mathrm{C}_{12}$-ketones 100 and 105 in nature occur in a similar manner (Figures 26 and 27).

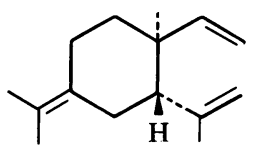

101

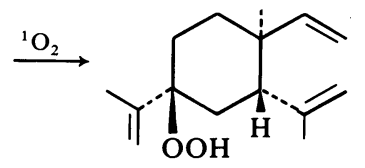

102

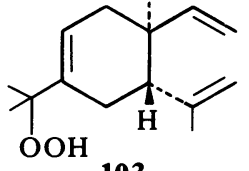

103

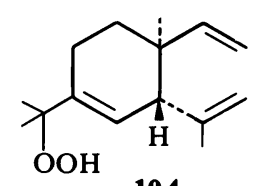

104

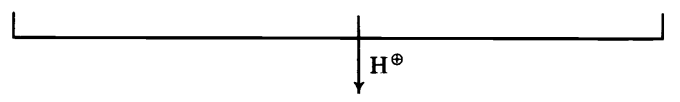<smiles>CC1=CC=CC2CCC(=O)C[C@H]12</smiles>

105<smiles></smiles>

106

(-)-geijerone

Figure 27. Formation of (-)-geijerone (105) by dye-sensitized photo-oxygenation of $(+)-\gamma$ elemene (101) via three tert-allylic hydroperoxides (102-104)

A biogenetic pathway to geijerone (105) involving Cope rearrangement of the corresponding cyclodecanone (106) is improbable, because the natural product is optically active. The $[\alpha]$ value of the natural ketone is identical with that of the synthetic material obtained from $(-)$-elemol or $(+)-\gamma$-elemene (101) within experimental error.

The thermal fragmentation of 1,2-dioxetan (Figure 1, A) yields electronically excited carbonyl compounds ${ }^{57}$, the activation energy of which can be transmitted to educts under suitable conditions. The principle of 'photochemistry without light' has already been recognized as being important for preparative organic chemistry and specially for biochemistry ${ }^{58}$.

A first example taken from dioxetan chemistry and capable of being transposed to the industrial scale will now be discussed ${ }^{59}$ (Figure 28). It was indeed possible to convert 1,4-dioxene 108, which is easily accessible from cyclododecanone (107), into the macrocyclic dilactone 111. The double bond in 1,4-dioxene 108 was found to be an excellent acceptor system for ${ }^{1} \mathrm{O}_{2}$. After the rapid absorption of one mole of oxygen, the two crystalline peroxides (109 and 110) form in a proportion of about 3:1 as the main products. Above $180^{\circ} \mathrm{C}$ the 1,2 -dioxetan system of 109 collapses and is converted to 


\section{G. OHLOFF}<smiles>O=C1CCCCCCCCCCC1</smiles>

107<smiles>C1CCCC2=C(CCCCCC2)OCC1</smiles>

108

$\downarrow \mathrm{O}_{2} / \mathrm{EtOH}$

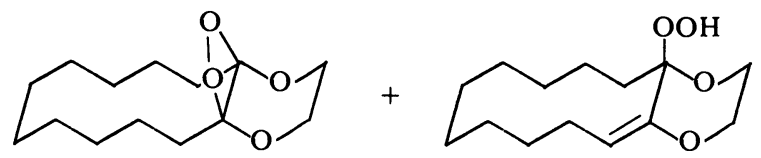

109

110<smiles>CCCCCCCCCC(=O)OCCOC(=O)CCCCCCCC</smiles>

$\mathrm{BF}_{3} \cdot(\mathrm{Et})_{2} \mathrm{O}$

111<smiles>CCCC12CCCCCC(OCCO1)C(=O)OCC2</smiles>

A

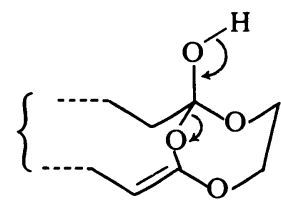

B

Figure 28. 1,2-Dioxetan and allyl hydroperoxide fragmentation. Synthesis of 2,5-dioxacyclohexadecan-1,6-dione (111) from cyclododecanone (107)

the dilactone (111) by a rearrangement as shown in A. The simultaneously formed allyl hydroperoxide (110) undergoes in the presence of boron trifluoride complexes a Criegee-type fragmentation (B) to give the same dilactone (111) in quantitative yield. This C-14 dilactone (111) is an easily accessible new musk fragrance of a known type ${ }^{60}$.

\section{REFERENCES}

1 (a) G. O. Schenck. Angew. Chem. 69, 579 (1957);

(b) K. Gollnick and G. O. Schenck in 1,4-Cycloaddition Reactions (ed J. Hamer), p 255. Academic Press: New York (1967).

(c) C. S. Foote, Accounts Chem. Res. 1, 104 (1968).

2 A. P. Schaap and P. D. Bartlett, J. Amer. Chem. Soc. 92, 6055 (1970).

${ }^{3}$ S. Mazur and C. S. Foote, J. Amer. Chem. Soc. 92, 3225 (1970).

${ }^{4}$ H. M. R. Hoffmann, Angew. Chem. Internat. Ed. 8, 556 (1969).

5 G. O. Schenck, K. Gollnick, G. Buchwald, S. Schroeter and G. Ohloff, Ann. Chem. 674, 93 (1964).

6 R. W. Murray and M. L. Kaplan, J. Amer. Chem. Soc. 91, 5358 (1969).

${ }^{7}$ H. Kautsky, Biochem. Z. 291.271 (1937); Chem. Abstr. 31, 7937 (1973), and previous papers. 


\section{SINGLET OXYGEN: A REAGENT IN ORGANIC SYNTHESIS}

${ }^{8}$ G. O. Schenck and K. Ziegler, Naturwissenschaften, 32, 157 (1954); G. O. Schenck, Angew. Chem. 64, 12 (1952).

9 N. Kornblum and H. E. DeLaMare, J. Amer. Chem. Soc. 73, 880 (1951).

10 L. Horner and W. Jurgeleit, Ann. Chem. 591, 138 (1955).

11 G. O. Pierson and O. A. Runquist, J. Org. Chem. 34, 3654 (1969).

12 G. Ohloff and G. Uhde, Helv. Chim. Acta, 48, 10 (1965).

13 G. O. Schenck and D. E. Dunlap, Angew. Chem. 68, 248 (1956).

14 K. H. Schulte-Elte, B. Willhalm and G. Ohloff. Angew. Chem. 81, 1945 (1969); Angew. Chem. Internat. Ed. 8, 985 (1969) (in English).

15 W. R. Adams and D. J. Trecker, Tetrahedron, 27, 2631 (1971).

$16 \mathrm{~K}$. H. Schulte-Elte and G. Ohloff, unpublished results.

17 M. Schlosser and K. F. Christmann, Ann. Chem. 708, 1 (1967).

18 G. Ohloff and M. Pawlak, Helv. Chim. Acta, 56, 1176 (1973).

19 W. G. Jennings, R. K. Creveling and D. E. Heinz, J. Food Sci. 29, 730 (1964).

${ }^{20}$ F. Näf, R. Decorzant and G. Ohloff, publication in preparation for Helv. Chim. Acta.

21 Y. Chrétien-Bessière, J. Garnero, L. Benezet and L. Peyron, Bull. Soc. Chim. Fr. 97 (1967); Y. R. Naves, Bull. Soc. Chim. Fr. 3152 (1967);

P. Teisseire, B. Cobier and M. Plattier, Recherches (Paris), 5 (1967);

F. Näf, R. Decorzant, W. Thommen, B. Willhalm and G. Ohloff, Helv. Chim. Acta, 58, 1016 (1975).

22 K. H. Schulte-Elte and G. Ohloff, Helv. Chim. Acta in press.

23 W. Skorianetz, K. H. Schulte-Elte and G. Ohloff, Helv. Chim. Acta, 54, 1913 (1971).

${ }^{24}$ N. Harada. S. Suzuki, H. Üda and H. Üeno, J. Amer. Chem. Soc. 94, 1777 (1972).

25 U. Burger and C. Jefford, Chimia, 25, 304 (1971).

26 R. B. Woodward and R. Hoffman, Angew. Chem. 81, 797 (1969).

27 W. Skorianetz and G. Ohloff, Helv. Chim. Acta, 58, 1272 (1975).

28 G. Helms, Dissertation, Göttingen (1961), mentioned in ref. $1 \mathrm{~b}$.

${ }^{29}$ K. H. Schulte-Elte. Dissertation, Göttingen (1961). mentioned in ref. 1b.

30 E. Demole, C. Demole and D. Berthet, Helv. Chim. Acta, 56, 265 (1972).

31 R. R. Johnson and J. A. Nicholson, J. Org. Chem. 30, 2918 (1965).

$32 \mathrm{~K}$. Kondo and M. Matsumoto, JCS Chem. Commun. 1332 (1972).

33 C. S. Foote, M. T. Wuesthoff, S. Wexler, I. G. Burstain, R. Denny, G. O. Schenck and K. H. Schulte-Elte, Tetrahedron, 23, 2583 (1967).

34 G. O. Schenck. Ann. Chem. 584, 156 (1953).

${ }^{35}$ K. H. Schulte-Elte, W. Giersch and G. Ohloff, unpublished results.

${ }^{36}$ S. H. Schroeter, R. Appel, R. Brammer and G. O. Schenck, Ann. Chem. 697, 42 (1966).

${ }^{37}$ G. O. Schenck, O. A. Neumüller. G. Ohloff and S. Schroeter, Ann. Chem. 687, 26 (1965).

38 Y. R. Naves and A. Grampoloff, Bull. Soc. Chim. Fr. 37 (1960).

39 G. Ohloff, M. Pawlak and A. F. Thomas, unpublished results.

40 T. Petrzilka, W. Haeflinger, C. Sikemeier, G. Uhloff and A. Eschenmoser, Helv. Chim. Acta, 50, 719 (1967).

T. Petrzilka and C. Sikemeier, Helv. Chim. Acta, 1461 and 2111.

41 C. F. Seidel and M. Stoll, Helv. Chim. Acta, 40,1990 (1957).

42 C. F. Seidel, D. Felix, A. Eschenmoser, K. Biemann, E. Palluy and M. Stoll. Helv. Chim. Acta, 44, 598 (1961).

43 G. Ohloff, E. Klein and G. O. Schenck, Angew. Chem. 73, 578 (1961).

44 E. Demole, unpublished results.

45 E. Demole, P. Enggist, U. Säuberli, M. Stoll and E. sz. Kováts, Helv. Chim. Acta, 53, 541 (1970).

46 K. H. Schulte-Elte, B. L. Müller and G. Ohloff, Helv. Chim. Acta, 54, 1899 (1971).

47 A. Nickon and W. L. Mendelson. J. Amer. Chem. Soc. 87, 3921 (1965).

48 C. S. Foote and S. Y. Wong, Amer. Chem. Soc. Div. Petrol. Chem. Prepr. 14, (2), A 93 (1969).

49 K. H. Schulte-Elte, unpublished results.

${ }^{50} \mathrm{~K}$. H. Schulte-Elte, M. Fracheboud and G. Ohloff, unpublished results.

51 B. Maurer, M. Fracheboud, A. Grieder and G. Ohloff, Helv. Chim. Acta, 55, 2371 (1972).

52 H. Hock and S. Lang, Ber. Dtsch. Chem. Ges. 75, 300 (1942); 77. 257 (1944);

H. Hock and H. Kropf, Angew. Chem. 69, 313 (1957).

53 R. Criegee, Ann. Chem. 560, 127 (1948).

54 G. Ohioff, J. Becker and K. H. Schulte-Elte, Helv. Chim. Acta, 50, 705 (1967).

55 A. F. Thomas, Helv. Chim. Acta, 55, 2429 (1972). 


\section{G. OHLOFF}

56 G. Ohloff, Ch. Vial and A. F. Thomas, unpublished results.

57 K. R. Kopecky and C. Mumford, Canad. J. Chem. 47, 709 (1969).

58 E. H. White, J. D. Miano, C. J. Watkins and E. J. Breaux, Angew. Chem. 86, 292 (1974).

59 J. Becker and G. Ohloff, unpublished results.

${ }^{60}$ G. Ohloff in Fortschritte der Chemischen Forschung, Vol. 12/2, pp 185-251, SpringerVerlag: Berlin (1969). 